\title{
Cost evaluation of alternative production methods
}

\author{
Lenau, Torben; Haudrum, Jan
}

Published in:

Materials \& Design

Link to article, DOI:

10.1016/0261-3069(94)90008-6

Publication date:

1994

Document Version

Peer reviewed version

Link back to DTU Orbit

Citation (APA):

Lenau, T., \& Haudrum, J. (1994). Cost evaluation of alternative production methods. Materials \& Design, 15(15), 235-247. https://doi.org/10.1016/0261-3069(94)90008-6

\section{General rights}

Copyright and moral rights for the publications made accessible in the public portal are retained by the authors and/or other copyright owners and it is a condition of accessing publications that users recognise and abide by the legal requirements associated with these rights.

- Users may download and print one copy of any publication from the public portal for the purpose of private study or research.

- You may not further distribute the material or use it for any profit-making activity or commercial gain

- You may freely distribute the URL identifying the publication in the public portal

If you believe that this document breaches copyright please contact us providing details, and we will remove access to the work immediately and investigate your claim. 


\section{Cost evaluation of alternative production methods.}

Mr. Torben Lenau, Ph.D.

Institute for Manufacturing Engineering

Technical University of Denmark

Building 425, DK-2800 Lyngby

Denmark

Tlf. $+4542882522 \times 4811$

Fax. +4545933435

Mr. Jan Haudrum, M.Sc.

Institute for Manufacturing Engineering

Technical University of Denmark

Building 425, DK-2800 Lyngby

Denmark

Tlf. $+4542882522 \times 4811$

Fax. +45 45933435

Correspondence and proofs should be send to Torben Lenau 


\title{
Cost evaluation of alternative production methods.
}

\author{
Torben Lenau and Jan Haudrum \\ Institute for Manufacturing Engineering, Technical University of Denmark \\ Building 425, DK-2800 Lyngby, Denmark. Tlf. +45 42882522 Fax. +45 45933435
}

Paper for the journal "Materials \& Design", special issue on Materials, Processing and the Environment, received 14 February 1994; Accepted 5 July 1994.

\begin{abstract}
:
Selecting the best of alternative production methods is becoming an increasingly important subject in developing competitive products. Different attempts are being made to supply designers and process planners with methods and tools which will help them explore alternative production processes. A key issue is the evaluation of such alternative ways of producing proposed components. The paper will discuss this topic and present an overview of cost calculation methods with emphasis on the evaluation of components produced by different production methods. Furthermore, is a practical method for evaluating alternative production methods suggested by the authors.
\end{abstract}




\section{INTRODUCTION}

The most important evaluation parameter for products is their cost. The product can have excellent properties but if the cost is to high, i.e. the profit is to low, there is no point in producing it. Cost estimation is therefore a very important subject which has been addressed from many different viewpoints. In this paper, we will take a general look at previous work done on cost calculation methods that can be applied to the different stages in product development, and in particular we will focus on cost calculation methods for evaluation of production methods. Finally, we present a practical cost estimation method to be used for selection among alternative production methods.

\section{Classification of costing methods}

In this paper, we have found it appropriate to classify cost estimation methods based on which stage of the product development it is used as shown in table 1. This is similar to the classification suggested by Ehrlenspiel [1]. Esawi [2] describe a slightly different method where the methods are classified based on their precision and amount of required information as either macro-, meso- or micro-scaling methods. The proposed classification complies with the Pahl \& Beitz design methodology [3].

At the very early product development stages where the development task is clarified and for instance an initial market investigation is carried out, rough estimation methods can suggest a cost level for the proposed product. Such methods can be based on a comparison of the product idea with similar products on the market (same product function, same technology or same material), or on a parametric function using parameters like product weight, material type, technology contents, etc. The result is an indication of a market price for the intended product, and will therefore include both direct and indirect costs (overhead) as well as profit. The cost figure will of course be imprecise but can be valuable for decisions about whether to develop the product or not.

Next step in product development is the generation and evaluation of alternative product concepts. Here can so-called functional costing methods be used. For well-known function like bearings or linear actuators costs can be calculated based on a few input parameters.

Table 1. Cost estimation methods for different product development tasks.

\begin{tabular}{|l|l|}
\hline Product development task & Cost estimation method \\
\hline $\begin{array}{l}\text { 1. Clarification of the task and product } \\
\text { planning }\end{array}$ & $\begin{array}{l}\text { Comparison with existing products } \\
\text { Life cycle costing }\end{array}$ \\
$\begin{array}{l}\text { 2. Conceptual design, evaluation of } \\
\text { alternative design concepts }\end{array}$ & $\begin{array}{l}\text { Functional costing, relative costing, life cycle } \\
\text { costing }\end{array}$ \\
3. Embodiment design, Process selection & Quick costing, relative costs, absolute costs \\
\hline $\begin{array}{l}\text { 4. Detailed design, Cost rationalization, } \\
\text { Design for Fabrication }\end{array}$ & $\begin{array}{l}\text { Cost structures, feature based costing, design } \\
\text { for cost, variant evaluation }\end{array}$ \\
\hline
\end{tabular}

Both for the task clarification and the evaluation of product concepts the most common has been to look at the costs related to the development and the production of the product. But in more and more cases, it becomes apparent that the customer looks at the cost in buying, using and disposing the product (e.g. the energy use and the CFC loss from a refrigerator) and therefore whole life cycle cost, which include development, production, distribution, use and 
disposal becomes the true evaluation criteria for the company. Life cycle costs has for many years been used for aircraft, military equipment and building construction, but it is becoming important also for more low-cost appliances due to increasing energy costs and more widespread environmental concern. For example, is energy consumption now an important sales factor for electrical devices.

At the embodiment design level costs are evaluated and compared for different materials and processing sequences. Designers often tend to use the few materials and processing sequences they are familiar with, and methods that can show the value of considering and selecting other alternatives are therefore important.

At the detailed design level cost estimation is primarily targetted towards optimization of the design of single parts with respect to the chosen production method, and the cost methods can therefore in some cases tell the designer how to change the design in order to achieve cost savings.

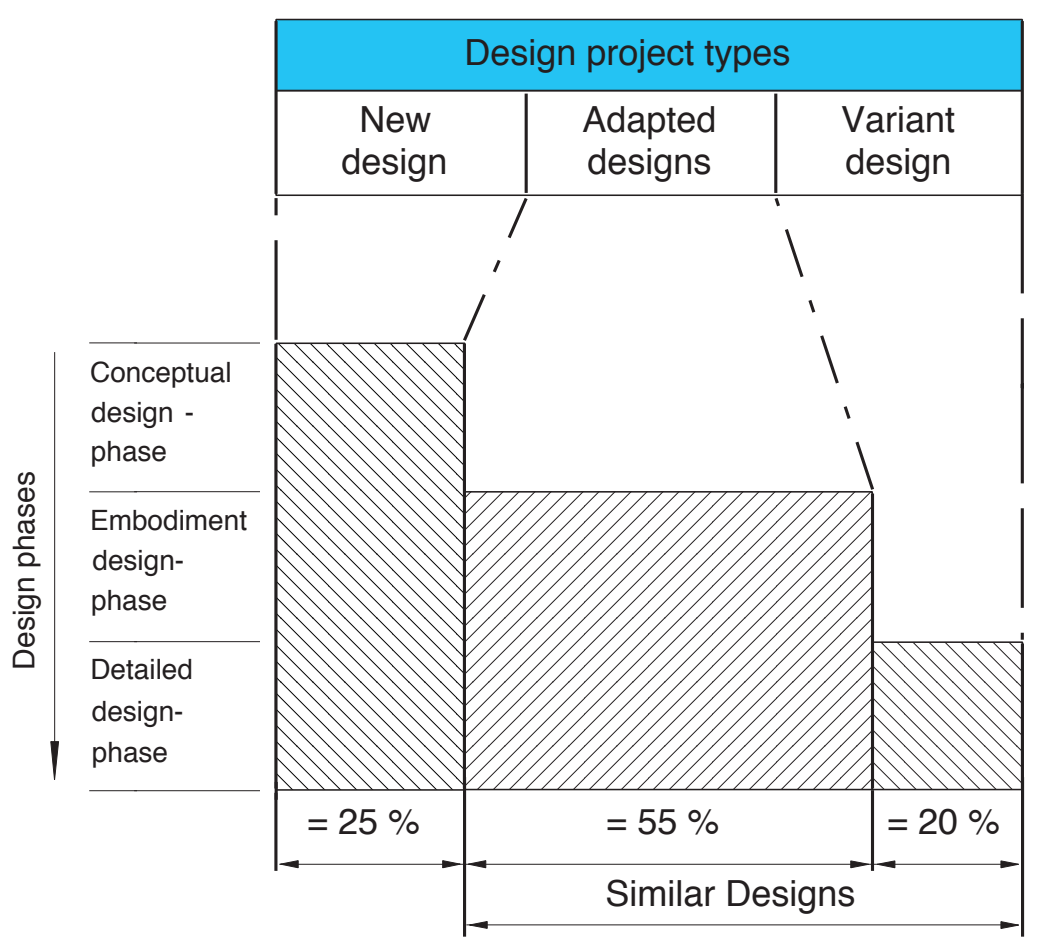

Figure $125 \%$ of design work is concerned with new products [4].

\section{Reuse of existing cost information}

Not all costs have to be calculated from scratch since a cost history exist for previous products. This knowledge can be utilized for variant design and redesign of products in conceptual design and the subsequent steps in product development. According to Diels [4] is only $25 \%$ of product design projects concerned with new products and $75 \%$ is either variant design or modifications of existing products. This means that cost figures for existing products can be a valuable information source in the majority of the design cases.

\section{Basic types of costs}

In general, cost can be calculated as either absolute costs or relative costs. Both types are most often calculated by using a parametric function, i.e. a function where the cost depends on one or more descriptive parameters. This can be called parametric costing and depicts the principle that a mathematical function calculates a cost estimate based on (a few) important product characteristics. 
An absolute cost figure is measured in cost units (e.g. $£$ or $\$$ ) in contrast to relative cost figures which has no unit. Relative costing depicts a calculation of a cost figure for an object relative to another known object, e.g. the cost of a gear wheel relative to another known gear wheel. Relative costs have the advantage that they tend to be independent of absolute cost levels and therefore of price development. This makes it easier to create lists of material cost or processing cost. A disadvantage for relative costs is that it cannot be decided whether the cost is low enough to actually manufacture and sell the product to a reasonable price but only to compare different solutions.

\section{METHODS USED IN INITIAL DESIGN PHASES}

This section is intended to give an overview of cost estimations methods for early design phases in order to differentiate them from the methods for embodiment and detailed design phases. After a discussion of the life cycle costing principle, costing methods for task clarification and conceptual design phases (which calculates subset of the life cycle cost) are described.

\section{Life cycle costing}

Life cycle costing can be applied to both task clarification and conceptual design phases. Life cycle cost depicts the principle that all costs related to the manufacture, distribution, use, maintenance and disposal for a single product are considered. Bush and Sheldon [5] describes the need for a methodology to be used by the designer when considering life cycle cost. The requirements to such a framework include handling of not only the product but the total system which the product is part of, that the cost model is simple enough to understand but yet precise, that relationships between cost consuming activities and design parameters can be handled and that the accuracy of the results should be apparent. Sheldon et al. [6] describes the type of cost to be included in life cycle costing and illustrate the problems of allocating the overhead cost: Adding 200-300\% overhead can destroy any good cost estimate. The cost estimation methods described in the following sections only calculate subsets of the life cycle cost, e.g. production cost or total company cost. 


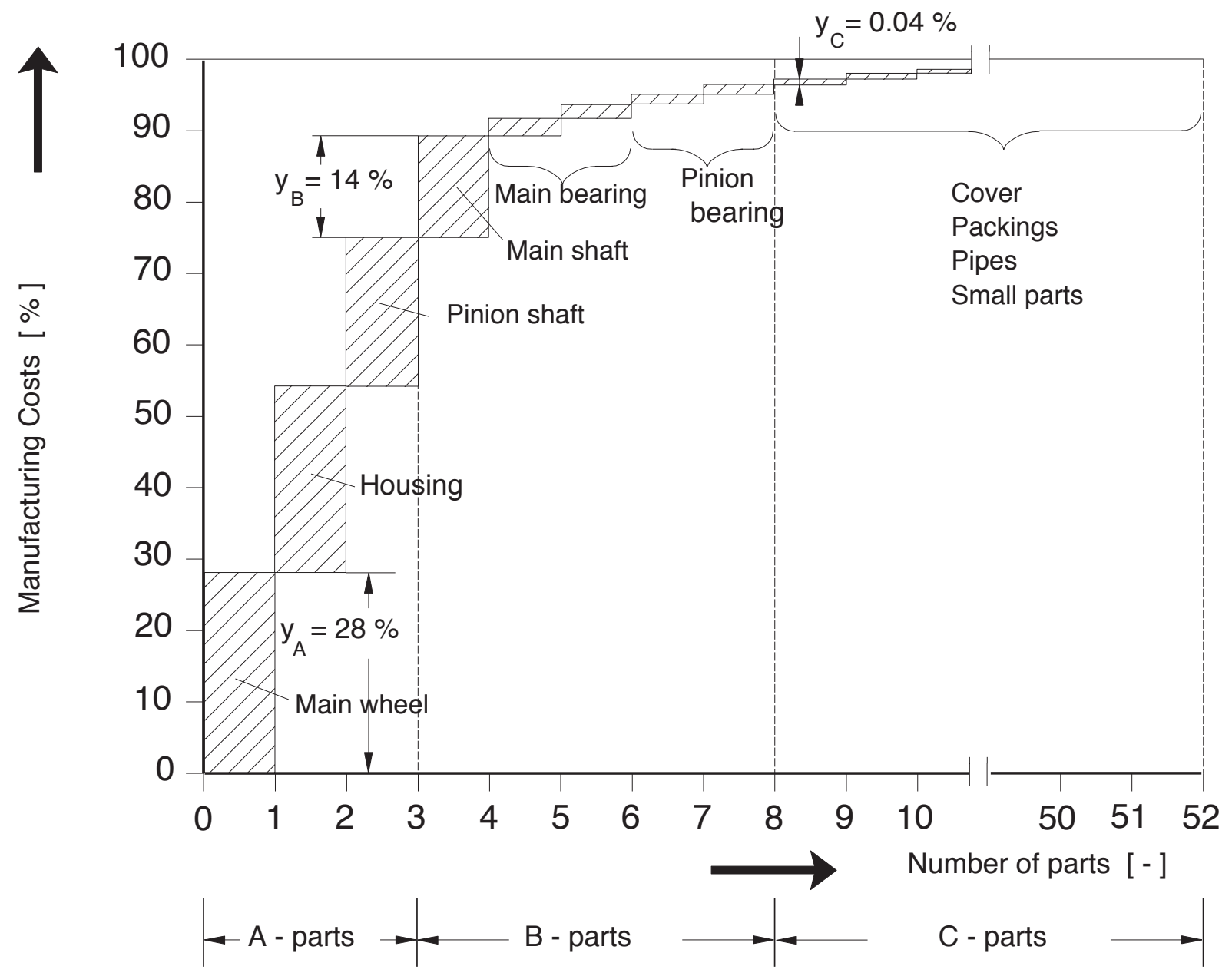

Figure 2 ABC-analysis for identification of cost heavy product elements [8]

\section{Task clarification and product planning}

At this stage, it is among other things decided where the emphasis should be put in the product development work. In some cases, especially for redesign, it is possible to identify areas for the product where the largest economical potentials are. A method for this purpose is the ABC-method proposed by VDI [7] and Ehrlenspiel [8]. The ABC-method is a general method for identifying cost heavy elements in the product, and should be used for redesign of existing products. It must not be mistaken with the Activity Based Costing mentioned by Bush [5], which is an alternative method for overhead accounting. In the ABC-method components and subsystems are divided into three groups $\mathrm{A}, \mathrm{B}$ and $\mathrm{C}$ depending on their cost level with objects in group A having the highest cost. The ABC-method is used to prioritize the effort in improving the product design and is reliable on access to cost information from previous products.

Another type of costing method for this design phase is the material cost share method described by Creese [9]. The method is based on the observation that the material cost share is fairly constant and significant for many groups of products, e.g. automobiles, machine tools, amplifiers, etc. Predicting the cost of a new product within one of these groups is simply done by estimating the material contents and dividing it its cost with the material cost share.

Measuring tools have for instance a material cost share of $20 \%$ and a new measuring tool with the estimated material contents of $\$ 2$ will therefore have an estimated cost of $\$ 10$.

\section{Conceptual design}

In this design phase cost estimation is related to more general product characteristics like 
product functions (functional costing) or subsystems or to a few characteristic parameters (quick costing). Quick costing depicts rough estimation techniques based on parameters like weight or volume. In some cases, can quick costing also be used in the task clarification phase. Functional costing is a method that estimate cost for parts or subsystems performing a certain function, e.g. gears for torque reduction. The advantage is that cost estimates can be calculated based on a few parameters which is known to the designer very early and that they are independent of the more specific selections of geometry and production methods. Functional costing can be used for three different purposes:

- Cost estimation directly from part specification (e.g. for quotations)

- Comparison of alternatives

- Detection of potential cost reduction areas (value analysis).

Fereirinha [10] reports a functional costing method developed for a Swiss machine tool producer, which is claimed to serve all three purposes. The example given is the lubrication function for the slide on a milling machine, where a cost function can be created based on knowledge about the cost of slide lubrication for different milling machines. Cost calculation based on product functions is possible here because the company has knowledge about the relations between the functions and the cost, due to the fact that they produce variants of the same product. The cost calculated here is probably fairly precise but is on the other hand specific to the company.

Ehrlenspiel [8] describes functional costing as a value analysis method to identify expensive areas of a product similarly to the ABC-analysis mentioned earlier in this article. The method is illustrated on a mechanical gear and examples of functions mentioned are torque enlargement and torque guidance. He emphasizes that functional costing for this purpose can only be applied when the functional structure and the cost of the solutions are known,i.e. existing products with known cost structures.

French [11] gives a good overview of functional costing and notes that obtaining data for functional cost is difficult except where the product or the component is identical with the function. He describes simple examples of different types of functional costs, where e.g. cost based on product specification is illustrated with the estimation of the cost of a single stage reduction gear as a function of the torque and the reduction ratio.

Li et al. [12] uses three examples to illustrate functional costing: Bearings, induction motors and linear actuators. Figures in Pound Sterling are given. For all three examples the name of the function and the component used to perform the function is identical. It is concluded that functional costs found for the three examples are accurate enough to be used for early estimates and comparisons.

Bradford and Culley [13] describe functional costs for power transmission systems as shown in figure 2. These costs are probably best suited for comparison of alternatives, even though the absolute cost figures also make quotations possible. 

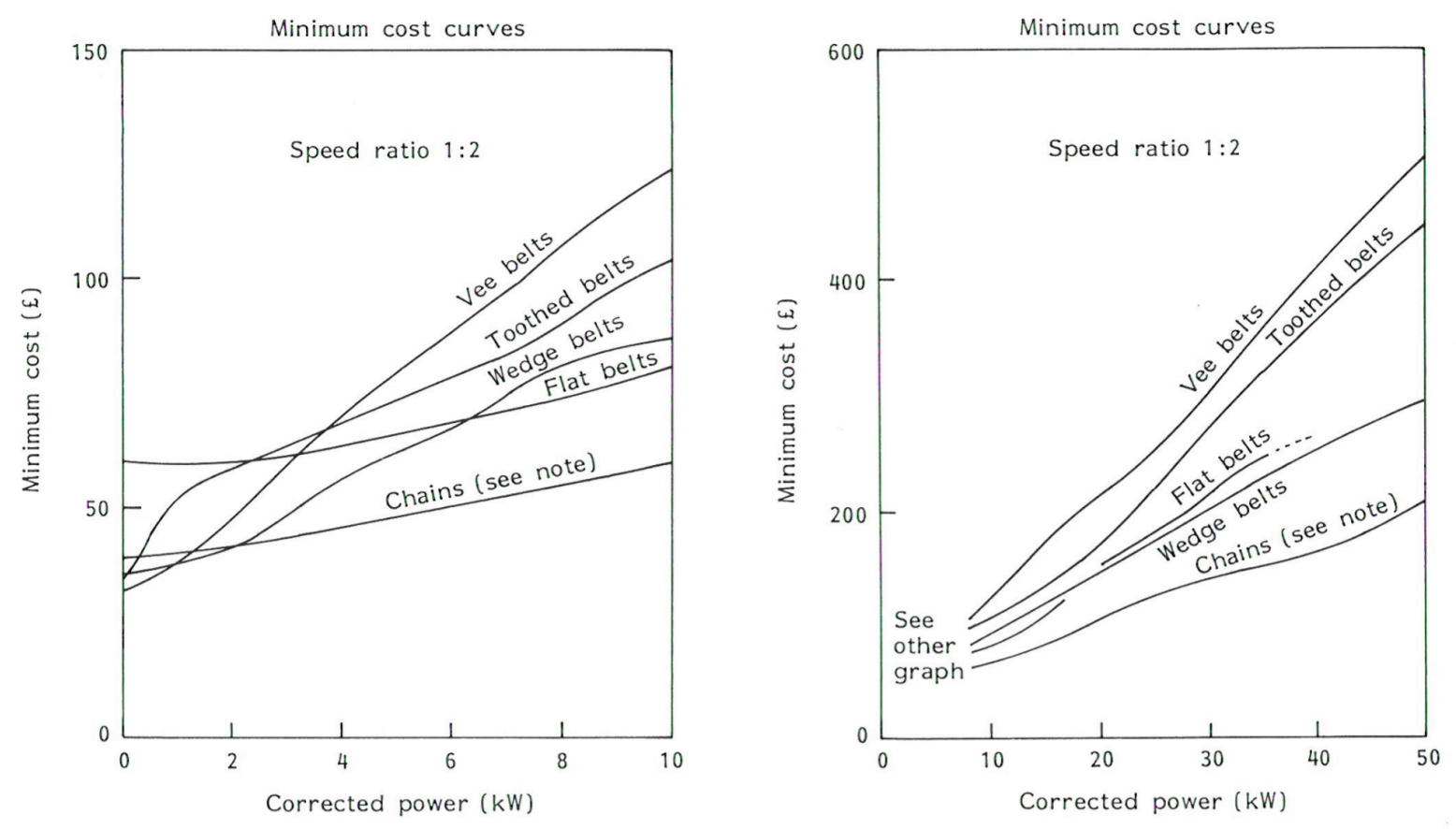

Figure 3 Functional cost curves for power transmission systems [13] Note: Chain costing does not include lubrication method: manual, drip feed, or oil bath and sump.

Esawi [2] describe an improved and more precise cost estimation method for functional costing which also includes considerations about cost levels for material, capital (equipment) and labor.

As it can be seen is functional costing only applicable to parts (or products) where a substantial amount of cost knowledge exists and clear cost structures can be defined, e.g. standard components. It is also a requirement that the functions are well defined and that reliable data can be accessed. Many standard components are characterized by performing a single main function, and often is the name of the component and the function identical. Functional costing is well suited to be used in the conceptual design phase to select among alternative concepts, to identify cost expensive elements and to calculate quotations, but functional costing is not suited for evaluation of production methods.

\section{METHODS FOR EMBODIMENT AND DETAILED DESIGN PHASES}

Within these two design phases both process selection and design for fabrication (DFF) activities take place. Of the cost calculation methods presented in literature some are suited for selection of production methods and others are suited for DFF (or design for cost).

The question is how much information is necessary about the product/part before the designer is able to make cost calculation and select a production method. It is obvious that the designer has to know the shape of the part. According to Jakobsen [14] there is a very close interrelation between shape, production method, material and function of a part and therefore these parameters have to be considered and selected simultaneously. Thus, when alternative production methods are evaluated, the shape of the part already at this stage has to be specified and have some level of producibility relative to the production method. It is therefore clear that the same component with the same shape cannot be evaluated for different production methods. And it is important that the different components compared through cost calculations have the same level of producibility to the respective production methods. 
Otherwise the designer would be comparing apples and pears.

To avoid this Haudrum et al $[15,16]$ suggests that the designer, on the basis of the given functions of the component, sketches a number of solutions consisting of material, production method and shape. With each of the relevant material/production method combinations in mind a number of shapes are sketched. This makes it more likely that the sketched solutions are actually produceable by the given production methods and that all solutions sketched for the different production methods have "the same" level of produceability. The shape of a die casted and an injection molded part might not be different at this sketching level, whereas a turned part and an injection molded part certainly will. When sketching only primary processes should be considered, i.e. the ones that produces main shapes. It is necessary though that the designer plans the whole sequence of production methods for each solution before the cost analysis; since one solution that seems cheaper when only considering the main production methods might show to be the more expensive one, when the whole production sequences are taken into consideration.

The cost calculation methods described in literature are in this paper presented and structured based on the production methods. Some methods (and these are the most interesting for the purpose of this paper) are treating more production methods to make it possible to compare them and these methods are presented in a separate section. The methods are briefly described, the purpose is outlined and if possible the input parameters are commented.

Table 2. Purpose and input parameters for 28 cost methods

\begin{tabular}{|c|c|c|c|c|c|c|c|c|c|c|c|c|c|c|c|c|c|c|c|c|c|c|c|c|c|}
\hline & & & $\mathrm{Ma}$ & chin & hing & & $\begin{array}{l}\text { Rolled } \\
\text { profiles }\end{array}$ & & Injec & tion & $\mathrm{mou}$ & aldin & & & owde & $\begin{array}{l}\text { rgy } \\
\text { rgy }\end{array}$ & Forgings & & $\begin{array}{l}\text { eet } \\
\text { etal } \\
\text { ork- } \\
\text { ng }\end{array}$ & $\begin{array}{c}\text { Die } \\
\text { castings }\end{array}$ & $\begin{array}{l}\text { Cast } \\
\text { ings }\end{array}$ & & $\begin{array}{c}\text { Sever } \\
\text { tion }\end{array}$ & $\begin{array}{c}\text { al pr } \\
\text { met }\end{array}$ & $\begin{array}{l}\text { roduc- } \\
\text { thods }\end{array}$ \\
\hline Reference no. & 23 & 24 & 25 & 26 & 271 & 221 & 272 & 28 & 29 & 30 & 222 & 31 & 32 & 33 & 223 & 34 & 34 & 36 & 224 & 225 & 273 & 37 & 38,39 & 40 & $41-43$ \\
\hline \multicolumn{26}{|l|}{ Input parameters } \\
\hline Dimensions & $\bullet$ & $\bullet$ & & $\bullet$ & & $\bullet$ & & $\bullet$ & $\bullet$ & $\bullet$ & $\bullet$ & $\bullet$ & & & $\bullet$ & $\bullet$ & $\bullet$ & & & $\bullet$ & & $\bullet$ & • & $\bullet$ & • \\
\hline Material & & 0 & & $\bullet$ & & $\bullet$ & $\bullet$ & & & & & $\bullet$ & $\bullet$ & & $\bullet$ & $\bullet$ & $\bullet$ & & $\bullet$ & $\bullet$ & & • & - & - & - \\
\hline Shape & $\bullet$ & $\bullet$ & & $\bullet$ & & $\bullet$ & $\bullet$ & $\bullet$ & $\bullet$ & $\bullet$ & $\bullet$ & $\bullet$ & $\bullet$ & & & $\bullet$ & $\bullet$ & & & & & $\bullet$ & • & - & $\bullet$ \\
\hline Surface quality & $\bullet$ & & & $\bullet$ & & & & $\bullet$ & • & $\bullet$ & $\bullet$ & & & & & & & & & $\bullet$ & & & $\bullet$ & & $\bullet$ \\
\hline Tolerance & $\bullet$ & & & $\bullet$ & & & & $\bullet$ & $\bullet$ & $\bullet$ & $\bullet$ & & & & $\bullet$ & & & & & $\bullet$ & & & $\bullet$ & & $\bullet$ \\
\hline Volume & & & & $\bullet$ & & & & & & & $\bullet$ & $\bullet$ & & & $\bullet$ & $\bullet$ & $\bullet$ & & & $\bullet$ & & • & & - & - \\
\hline Area & & & & & & & & & & & $\bullet$ & - & & & - & & $\bullet$ & & & $\bullet$ & & & & & \\
\hline Prod. vol./batch size & & & & $\bullet$ & & $\bullet$ & $\bullet$ & & & & & & $\bullet$ & & • & & & & & & & • & • & - & $\bullet$ \\
\hline Other parameters & & & $\bullet$ & $\bullet$ & & $\bullet$ & & & & & & & $\bullet$ & $\bullet$ & $\bullet$ & $\bullet$ & & $\bullet$ & $\bullet$ & $\bullet$ & & & $\bullet$ & & \\
\hline Not mentioned & & & & & $\bullet$ & & & & & & & & & & & & & & & & $\bullet$ & & & & \\
\hline \multicolumn{26}{|l|}{ Purpose } \\
\hline Process selection & & & & $\circ$ & & & & & & & & 0 & 0 & & & $\bullet$ & & & & & & $\bullet$ & & - & $\bullet$ \\
\hline Quotations & $\bullet$ & & & & & & $\bullet$ & & & & & & & 0 & & & & & & & & & 0 & & \\
\hline Variant evaluation & & & & & & & & - & 0 & & & & 0 & & & & - & & & & & & & & \\
\hline Design for cost & $\bullet$ & $\bullet$ & & $\bullet$ & • & & & & & $\bullet$ & & & & $\bullet$ & & $\bullet$ & $\bullet$ & & & & & $\bullet$ & 0 & & \\
\hline Process planning & & & - & & & & & & & & & & & & & & & & & & & & - & & \\
\hline Not mentioned & & & & & & • & & & & & - & • & & & • & & & - & - & - & - & & & & \\
\hline
\end{tabular}

All methods are compared in Figure 4 where the reference numbers are shown. The figure gives a general view of the input parameters necessary to use the described cost calculation methods and it also shows the purposes of the described methods. The filled mark $(\bullet)$ indicates the purpose of the method when it was developed, and the open mark (o) indicates our impression of what the methods could be used for.

Some specific input parameters used in the methods are mentioned in the figure as other parameters. These are typically parameters which are not known by the designer in the stage where the production method is selected, (e.g. number of teeth on the cutter and cooling ability). Some papers have not described the input parameters; these are marked not mentioned.

The purposes of the described cost calculation methods is shown in the figure as: process 
selection, quotations, variant evaluation, design for cost and process planning.

It is recognized by several authors that the selection of production methods in the early phases of design has to be made with the knowledge of very few and quite rough parameters. This is characterizing the cost calculation methods marked process selection. Some of these methods treat only one single production method, whereas others treat more production methods. The parameters used in these methods are some basic ones: Shape, material, dimensions (diameter/width, length, height, wall thickness) and in some cases tolerances and surface quality. From these basic parameters, other parameters like: volume, weight, area etc. can be derived. Basic production parameters are production volume and batch size.

The methods marked quotations are methods suitable for subcontractors for cost calculations before giving a price to the buyer. Theoretically this kind of methods could be used for selecting processes as well, but the input parameters are typically parameters only known by production engineers. The quotations made by the subcontractors can naturally be used as basis for selecting the cheapest production method.

Some methods are usable for evaluating different solutions (shapes) within the same production method, these are called variant evaluation methods. The methods are relative methods and can only be used for comparing two alternative solutions for the same component. Thus, the methods are of no use when different production methods or different structures of the product are evaluated. The relative methods can only be used for the specific process they are developed for, thus if the part is produced by a production sequence a relative result for each production method in the sequence is of no value.

The design for cost methods have the purpose to help the designer make cheaper solutions within a given production method. The methods are of two types. The first one where it is possible to calculate cost, change the component and then make another calculation, and thereby obtain cheaper components. The second one where the system interactively tells the designer what features are the more expensive ones, and what changes would make the component cheaper.

In the methods dedicated to process planning the calculation is making it possible to select the cheapest route in the production; the cheapest machines and production parameters.

Boothroyd and Dewhurst are represented in the literature with several papers about cost calculation $[17,18,19,20,21]$, but since these papers only describe fractions of the calculation methods they are not described in this paper. Instead we have chosen to describe their computer system, where all these calculation methods have been realized [22]. The system for cost calculation includes modules for five different production methods: metal sheet working, injection molding, die casting, powder metallurgy and machining.

\section{Cost calculation methods for machining}

The method described by Spur and Kreisfeld [23] is developed for quotations and design to cost. It takes its starting point in the shape of a component. The shape is divided into an envelope shape and local features. Additional parameters like tolerance and surface quality are also needed. The authors claim that from a classification into 27 envelope shapes and 8 local features it is possible to calculate the cost of simple rotational parts. The paper does not describe how the calculations are made, but mentions that the deviation from actual cost is about $10 \%$. 
Kreisfeld [24] describes two methods for cost calculation of rotational parts. One method is based on a static and the other one on a dynamic classification of "cost families". The static one consists of 27 different groups describing length/diameter ratio, outer shape and inner shape. The dynamic one is valid in a computer, where the user selects the criteria used for the classification. According to the author these methods offers very good results. Except for the "cost family" classification, the paper does not clarify the algorithm behind the methods and the results.

Gopalakrishnan and Pathak [25] describes a computer system which, on the basis of features, will select the required process parameters for milling operations (process planning), and with these parameters calculate the cost. The inputs needed to run the program are very detailed (e.g. number of teeth on the cutter and number of resharpenings) and therefor the system is not useful for early cost estimates. The program is passive in the sense of design for cost, since it does not specify the expensive features on the part, instead the design has to be changed and the program executed again.

Ott and Hubka [26] describes a method for design to cost of turning, milling and drilling operations. On the basis of a number of parameters (number of machines, production volume, weight, material, volume, tolerances and shape in the sense of form features) values for different time parameters are given in a table. From these figures, it is possible to calculate the total manufacturing time including material cost.

Ehrlenspiel \& Rutz [27] presents a cost calculation system for rotational part. The input parameters are not described. Beside cost calculation the system also supports the user in the design for cost activity by suggesting changes on features that are too expensive to produce (e.g. "A cylinder here instead of a cone would save 2.58 DM" or "Doubling the production volume would save $3.49 \mathrm{DM} ")$.

The cost calculation program of Boothroyd \& Dewhurst includes a machining module which makes it possible to make two different calculations. One is a very rough cost estimate and the other is a more accurate analysis of the part. The rough estimate is made from the parameters shown in Figure 4 where the shape is chosen from a list of basic part shapes in the program. The more accurate calculation is made on more detailed inputs.

\section{Cost calculation methods for rolled profiles}

Ehrlenspiel and Rutz [27] presents a program for quotations on rolled profiles. The designer builds his profile from a set of standard profiles or standard features. From this input and information about material and batch size, the system is able to calculate the cost.

\section{Cost calculation methods for injection molding}

Poli and Fernandez [28] present a relative method to obtain the mold cost for injection molded parts. The method can be used to compare the tooling cost for two alternative variants. Through information about: component size, number of internal undercuts, number and type of external undercuts, amount of cavity detail, parting plane complexity, surface finish, tolerancing requirements, projected area and thickness of the mold base a six digit code is obtained. Each digit of the code has a cost associated with it, and the total tooling cost can be determined based on formulas involving all digits.

In Rosen et al [29] the same cost calculation method as in the above mentioned paper is described. The difference is that, from a design feature representation (CAD) of the part, a 
computer system automatically derives a representation in terms of manufacturing features and evaluate the manufacturing representation for tooling cost. The method can be used for Injection molding and die casting.

Poli et al [30] includes both the tool cost calculation method from [28] and a relative method for processing cost. The first one can be used very early in the embodiment stage the latter demands much more detailed information than available so early, e.g. questions like: "is the part easy/not easy to cool?" and "is the part difficult/not difficult to fill and eject ?". The question is if the tool cost has any valu in the early stages if the processing cost cannot be calculated.

The injection molding module in the Boothroyd \& Dewhurst cost calculation program requires (beside the parameters shown in figure 4) knowledge of the mold, e.g. if it is a 2plate or 3-plate mold, if it has hot runner system, the parting line factor, no. of unscrewing devices, etc., which means that it is suited for detail design and not for early estimates.

Johansen [31] presents a method for calculating material cost and processing cost. The method uses input parameters like dimensions, volume, area and material. The tooling cost has to be found as quotations from a tool maker and is not included in the method. Depending on the parameters that has to be specified for the tool maker, the method can be used for the selection of production methods. Johansen suggests that the user should present the result as a cost per part vs. production volume curve.

\section{Cost calculation methods for powder methallurgy}

Han et al [32] presents a method for spreadsheet based estimation of P/M processed parts. It is claimed that the cost consists of four factors namely: equipment, material (also including tools), energy and labor. The paper does not explain how these factors are obtained but it is obvious that it is for very detailed calculations since parameters like sintering temperature and molding pressure has to be specified.

The program Boothroyd \& Dewhurst program includes a module for calculating cost of powder metal parts. The user must possess quite a lot of knowledge about the processing, since parameters like: type of sintering furnace and the type of secondary processes and heat treatments have to be specified.

Knight [33] describes a procedure intended to be used at the early stages when alternative part configurations and processes are being considered. A number of different input parameters are needed but they all seem to be available on the very early stages of design. The evaluation of the method shows that the calculated results are quite close to the actual tooling cost, but unfortunately this evaluation does not include material cost and processing cost.

\section{Cost calculation methods for forgings}

Knight and Poli [34] presents a method for relative cost estimation method for forgings. Through classification codes based on part shape, size and specific features that affect manufacturing difficulty relative costs for various designs can be estimated. The method is very easily used on the early stages of the design process, but only for evaluating different forged parts. Using the method for process selection is not possible due to the relative costs, which cannot be compared with calculations made by other methods. 


\section{Cost calculation methods for sheet metalworking}

Haan [35] describes a system that can be used by designers to estimate the cost for stamped parts. No details are given on how the system works. He mentions some of the needed 18 input parameters, and many of them seem to be parameters that are not available in the early stages of design (e.g. strip dimensions, feeding increment, the kind of stops used). And since the estimated die cost must also be specified, the system could not be of much use in the early stages.

The Boothroyd \& Dewhurst program includes a module for sheet metal working. Using the sheet metal working module it seems that the designer has to know quite a lot about the production method. Many of the parameters that he has to specify are parameters more likely known by a production engineer e.g.: length pitch, with pitch, number of different punches, stock form, number of hits etc. and therefore the module is not suited for early cost estimates.

\section{Cost calculation methods for die castings}

The cost calculation program of Boothroyd \& Dewhurst includes a module for die casting. This module requires knowledge of almost the same parameters as the injection molding module although some of the more mold specific parameters are left out. It requires some level of processing knowledge, e.g. number of holes to be trimmed, parting line factor, side cores etc., but it seems to be parameters manageable for the designer even at early levels.

\section{Cost calculation methods for castings}

Ehrlenspiel and Rutz [27] describes a computer system with the purpose to make quick quotations. They do not mention what parameters are used as input, but they mention that one needs 45 parameters of which only 15 geometric, and that they have made another program with only 14 input parameters. They also want to couple the program with a CAD system. It seems to be necessary to specify very detailed designs in order to use the program.

Pacyna et al [36] present a method for variant evaluation as well as process selection. The dimensions of the component are transformed into three form characteristics: compactness, relative length and relative wall thickness. A set of formulas based on these and other parameters like: material, number of cores and casting class factor are presented. The method is developed for castings but the authors claim that the concept is useable for forging, welding, plastic parts and powder metallurgy parts as well.

\section{Cost calculation methods including several production methods}

Ferreirinha [37,38] describes how the HKB-system can be used for cost calculation. Included production methods are: turning, milling, casting, welding, forging, sheet metal forming and plastic parts. Inputs to the system are component parameters (shape, dimensions including tolerances, surface quality, heat treatments, quality features) raw material parameters (material, pre-processes, shape, maximum sizes, pretreatments) and production parameters (batch sizes, number of clampings). It is claimed in the papers that the method is usable in the embodiment design phase, but regarding the input parameters it is unlikely, that the system is developed for early estimates, and it would be unable to support the designer in the early calculations of production method alternatives.

Zenger [39] presents a system for comparison of different production methods on the basis of cost. With a few inputs like: production volume, average batch size, basic part dimensions, volume and simple geometric complexity values, the system is able to present comparable 
cost analyses for different combinations of material and production method for a given component and it is only possible to calculate combinations which are actually realistic. The system includes five different casting processes as well as machining, injection molding and sheet metal working. The material selection is made by general class such as aluminum, cast iron, copper, zinc, etc. The system is able to give different outputs to the designer: the cost is listed in order of least to most expensive combinations or a curve showing cost per part versus production volume for all combinations. It is not mentioned how close the analysis are to the actual production cost.

The program developed by Zenger is very close to the ideal concept for the designer. He is aware that the designer has to consider whole sequences of production methods before selecting a solution although this capability is not implemented in the system yet. The best part of the output is the curves showing cost per part versus production quantity for all investigated process/material combinations, since these curves makes it possible for the designer to see the sensitivity of changing the production volume. It seems that all process/material combinations are calculated on basis of the same component shape, and obviously, this means that the shape does not have the same level of producibility for all combinations and therefore the calculations could be misleading.

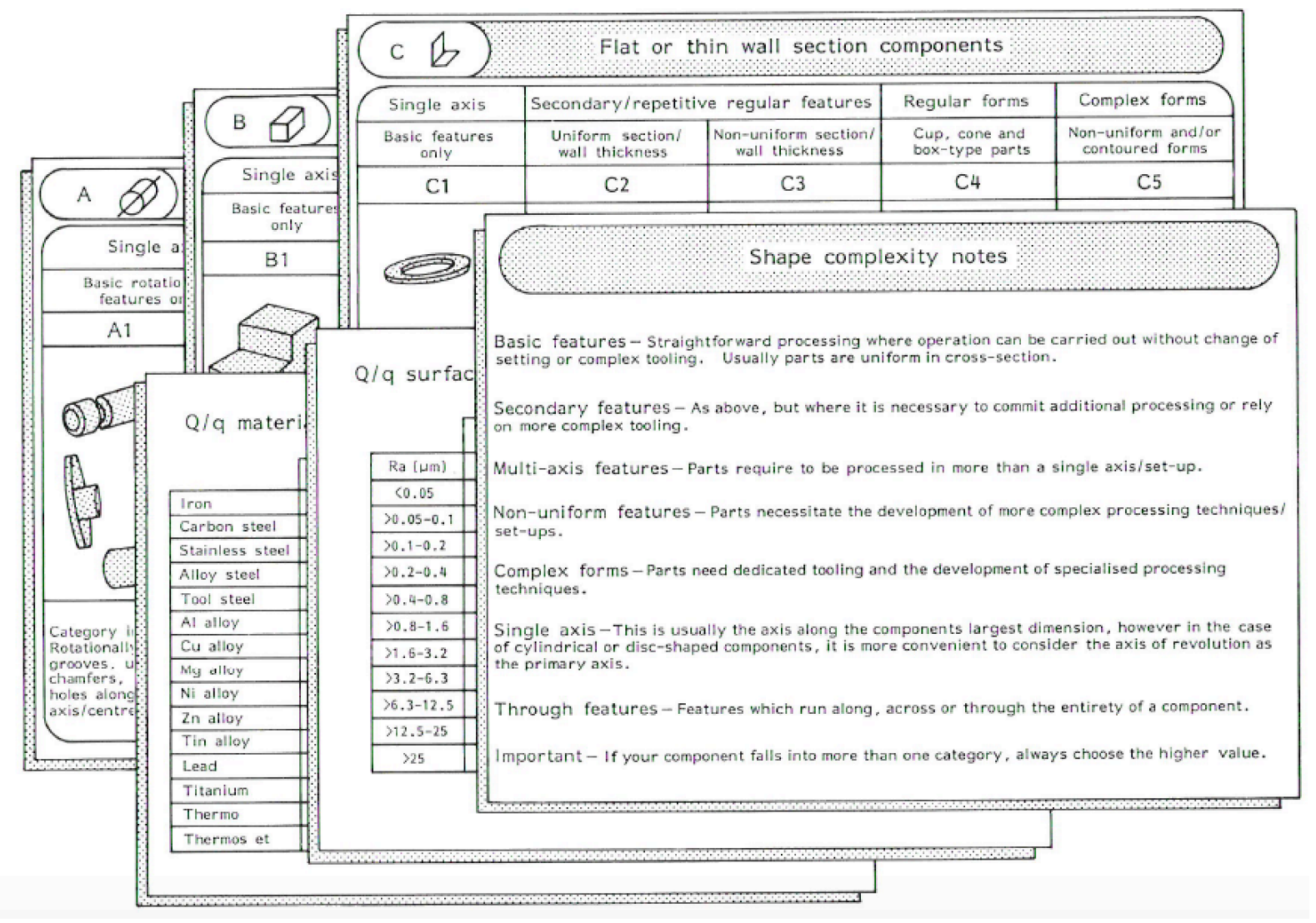

Figure 4 Input tables in the costing method from Hull University [40-42]

Allen et al $[40,41,42]$ present a technique for evaluating processes in the early stages of design. The papers give an overview of the concept and shows that the predicted costs lies very close (within 16 per cent) to actual costs (for plastic moulded and pressed sheet components). It is not described how the method is used, but private communication with $\mathrm{Mr}$. Allen has clarified the following: Calculations are based material cost and cost of production methods, where the latter is determined using a basic processing cost and design-dependent relative cost coefficient. The basic cost derived from the production method, the production 
volume and the relative cost coefficient are derived from material-process suitability, shape complexity, tolerances etc. The user does not have to know detailed information about the different production methods used to produce a component. For example, when evaluating a design, the user only has to select the primary production methods; any secondary production methods are automatically accounted in the metrics. Thus, the designer only has to select the primary production method and is simply made aware of the fact that it will be necessary to employ secondary processing for the design in the current form. The method seems to be very useful for designers in the selection of production methods.

Although Boothroyd and Dewhurst in their papers often claim that their cost calculation methods are intended to be used at the early design stages, it seems that most of the modules included in the cost calculation program need information about the production environment which is unavailable to the designer when production methods are selected. The machining and the die casting module are exceptions and seem to be usable for this purpose.

\section{Requirements to a cost calculation method for selection of production methods.}

Only a few papers are dealing with the problem of selecting production methods in the design phase $[26,31,33,36,39,40-42]$. Some are treating single and others several production methods. It seems that the methods/systems developed by Zenger and Allen et al are close to the concept we have in mind. From our point of view the ideal concept for cost calculation methods for selection among alternative production methods must fulfill the following criteria:

- It should be possible to compare parts sketched for different material/production method combinations which means that input parameters in general should be one or more of the following: rough material, rough shape, rough dimension, production volume, tolerances and surface quality.

- $\quad$ Sequences of production methods and not only single production methods should be treated, since a component that seems to be the cheapest one when comparing the main processes could be the more expensive one when comparing the whole processing sequences.

- $\quad$ Both cost for the product and sub-assemblies as well as cost for single parts should be available, which is necessary when components are integrated or disintegrated.

- $\quad$ Replacement and renovation of tools should be included. The number of components that can be produced by a tool (e.g. by injection molding) is limited and therefore the investment in renewal of the tools must be included in the calculation.

- $\quad$ The method should be trustable and make the sensitivity to the different parameters visible to the designer, e.g. it is essential that the designer can identify the cheapest solution if the production volume is increased or decreased.

Both Zenger and Allen et al have been concerned about the first two, but it seems that they have not been aware of the last three points. The next section will sketch our ideas of a concept for a method/system to support the designer in cost calculation as a basis for selecting production methods.

\section{A COST ESTIMATION METHOD FOR EARLY PROCESS SELECTION}


Based on the literature review and on case studies in several industrial companies $[43,44,45]$ we have identified the need for a fast cost estimation technique, which can be used to compare and rank different sequences of production methods. In the following a method that can be used for this purpose will be described. The method is based on a previous method developed for the MADED system [46,47]

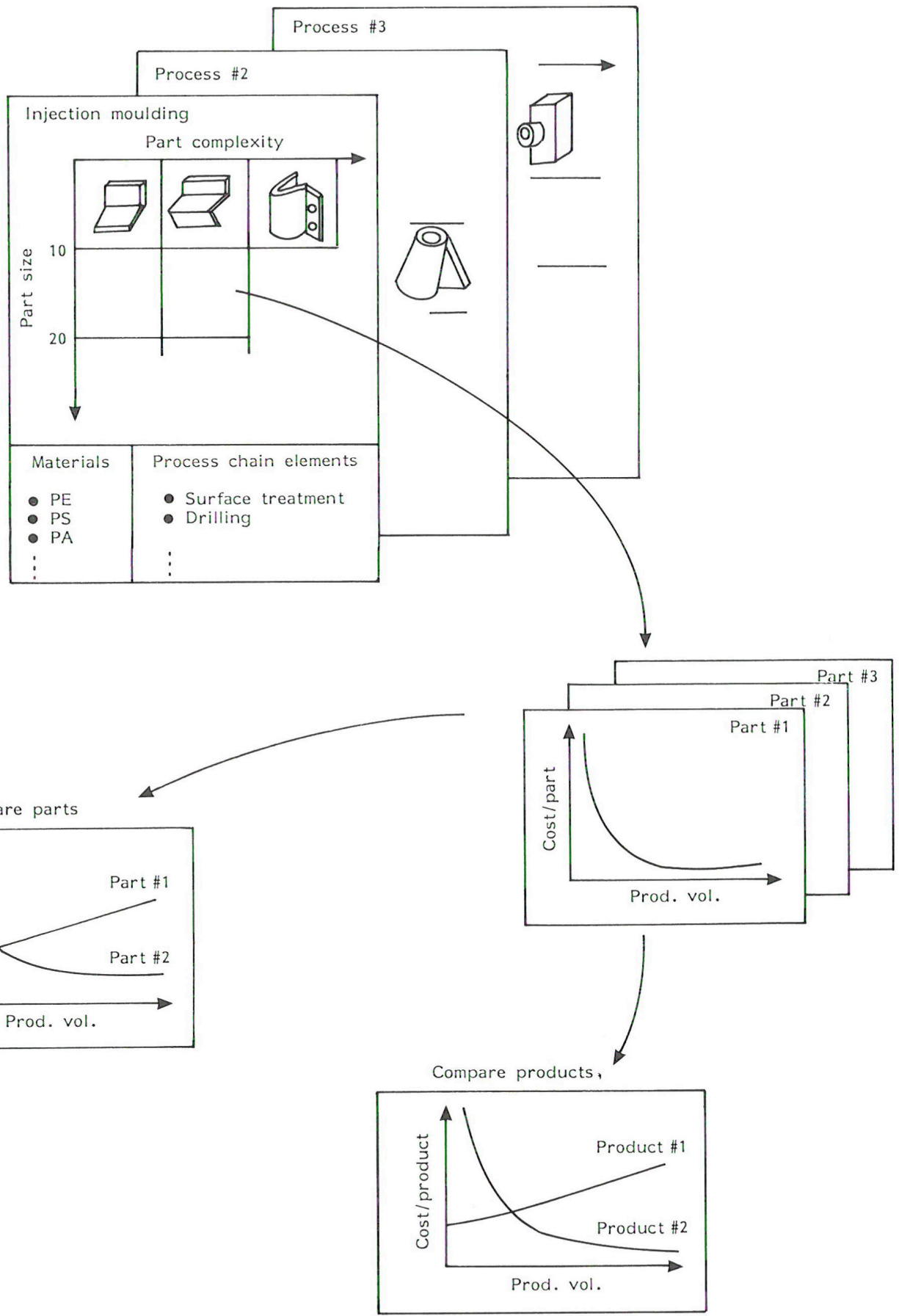

Figure 5 Entry tables and cost curves for the proposed cost evaluation method.

The method is based on the basic hypothesis described by Lund Jepsen [48] that a sequence of production methods (a process chain) is used to produce a part, but process selection is done by first selecting the primary production method used to produce the main shape of the part and select secondary processes hereafter. In the proposed method, the entry point is therefore to select the primary production method, and in the example shown in figure 6 injection 
molding has been selected. For each production method, a table describes typical parts in different sizes and with different geometrical complexity. An underlying hypothesis is that cost increases for growing size and increased geometrical complexity. The rows in the diagram represent the size of the part and the columns the complexity. For each cell, i.e. each typical component, a cost curve can be displayed, i.e. a curve showing the cost per part as a function of production volume. Material type can be selected before choosing one of the typical components and will then influence the cost curve. In a similar way, can additional production methods be selected and thereby influence the cost curve. This makes the method capable of handling the total sequence of production methods needed to produce the part.

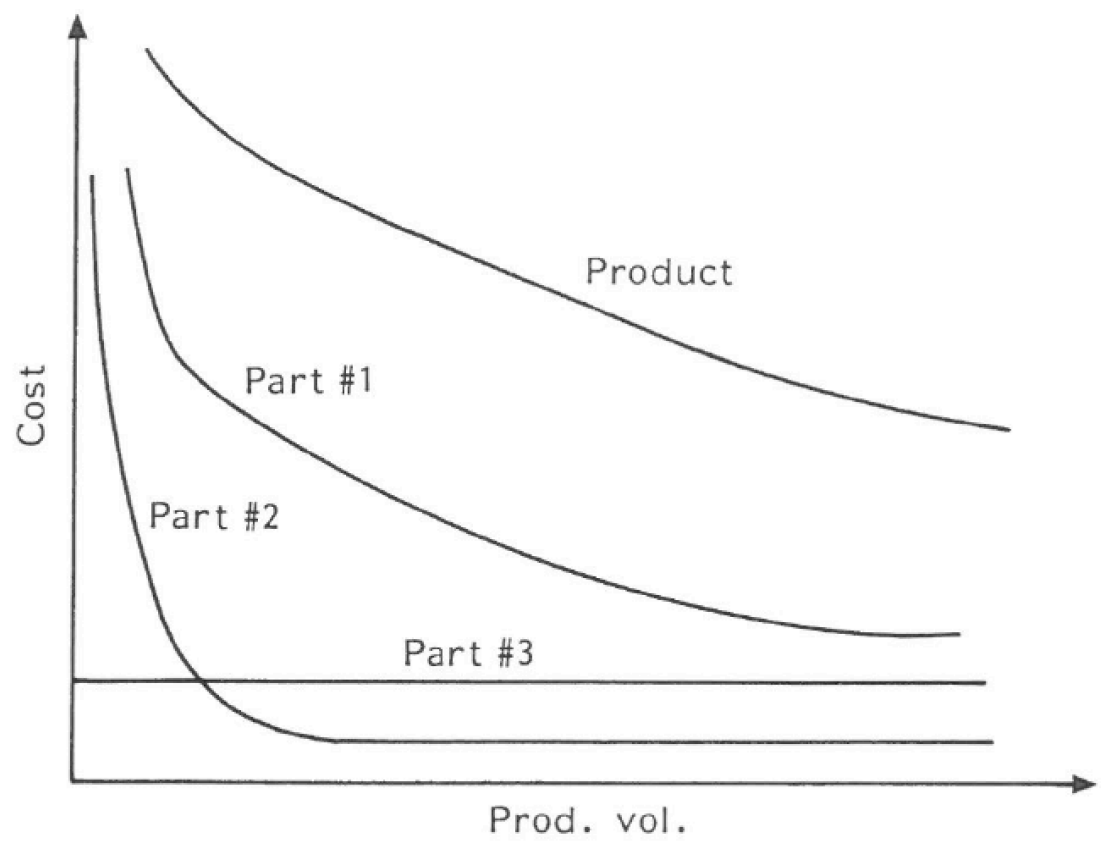

Figure 6 Cost curves for a product consisting of three parts.

Results are displayed as cost curves where the cost is shown as a function of production volume. Curves have a number of advantages compared to single results. When the cost algorithms work as a black box where the input is a number of parameters and the output a single figure, the disadvantage is that the result appear more precise than it is (the analogue/digital clock problem) and that there is no indication of what the uncertainty is. This is important since costs by nature are not very precise. Different companies have different costing policies and a company with free production capacity will probably give a better price. The curves solve this problem. Since it is difficult to make a precise reading from a curve the user will have a better understanding of the lack of precision. Furthermore, do the curves have the advantage that a certain degree of sensitivity analysis is possible and the designer can investigate what happens if product volume is halved or if a more complex geometry is selected.

It is possible to select several different typical parts for the same or for different production methods, and to display the resulting cost curves in the same diagram, which makes it easy to compare the costs. Furthermore, is it possible to group parts together as products, which means that the cost curves are added together and gives a picture of the cost for the total product as shown in figure 7 . The cost curves can be shown for single parts or for whole products and can therefore be used to compare alternative production methods for a specific part or to compare alternative products, and in that way, make sure that cost savings for one part in a product is not made by scarifying cost of another part in the product. It is also possible to consider the fact that components look different when produced by different 
processes, by comparing typical components from different tables.

Costs are calculated as the sum of tooling cost, total material cost and total production cost (labor + machine cost). This sum is divided by the production volume. The cost curves represent not only the cost of the primary production methods, but also includes any normally used additional production methods, e.g. sawing before turning. Other additional production methods are selected from a list as described before.
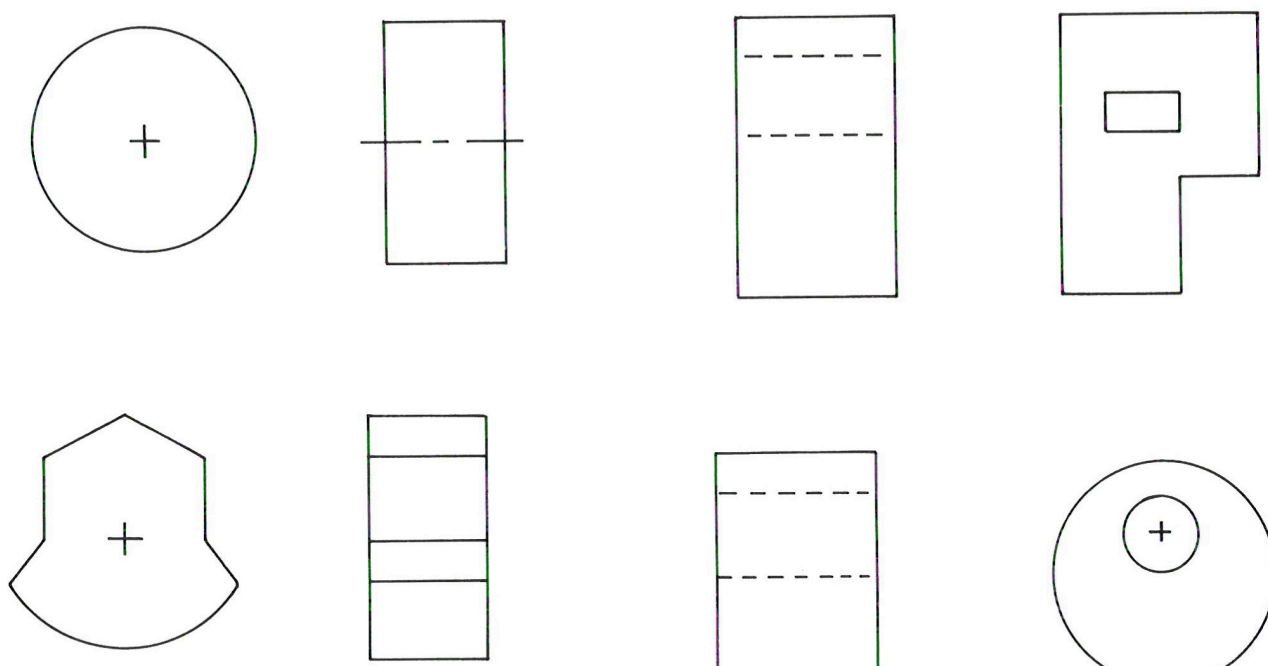

Class 1
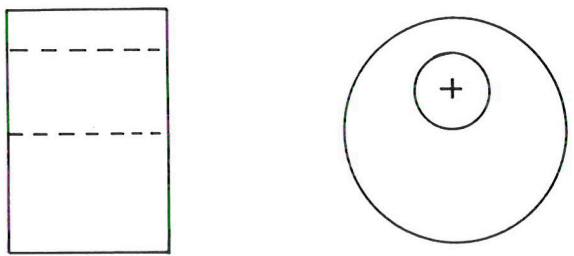

Class 2
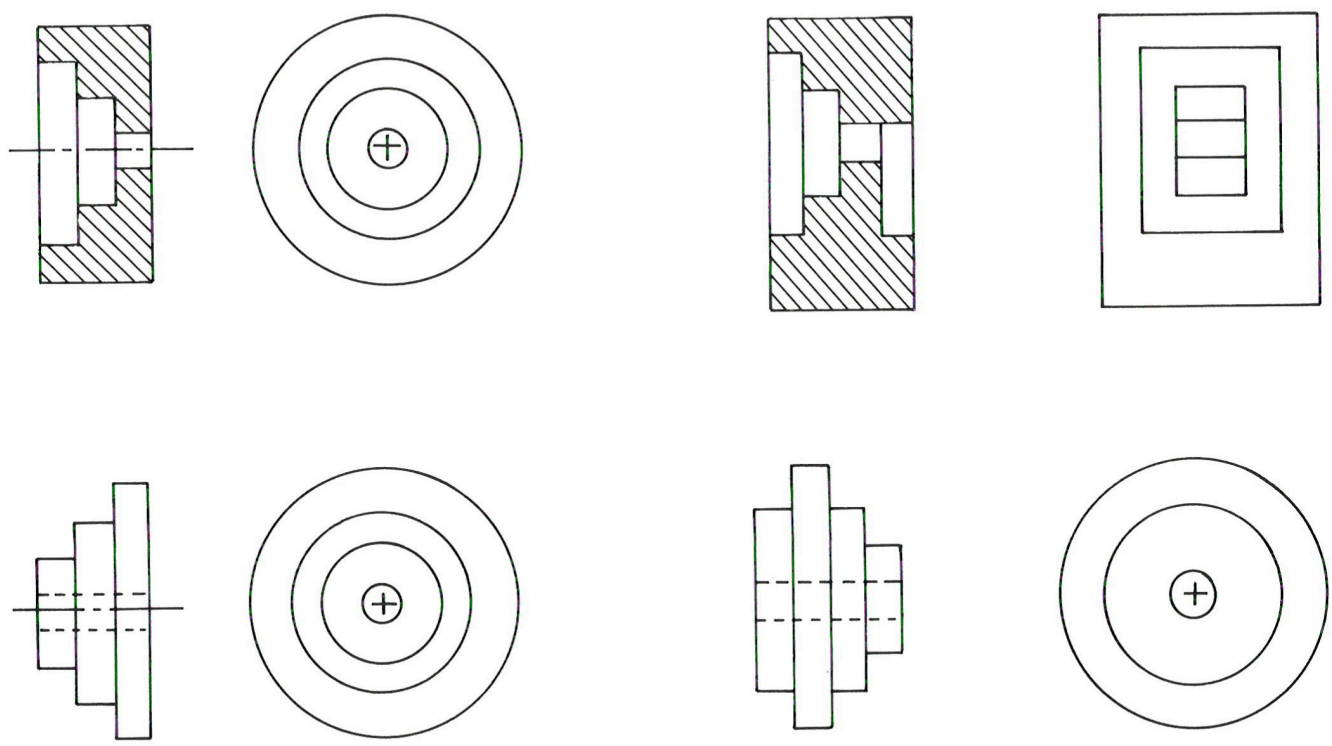

Class 3

Class 4

Figure 7 Geometric complexity classes for powder compaction [49]

Figure 8 shows an example of groups of geometric complexity for the powder compaction production method [49]. Parts belonging to group one are the most inexpensive to produce and parts in group four are the most expensive. In this case the tool becomes more expensive when more pistons are needed to do the compaction. In this way increased tooling cost can be handled fairly well except for one problem which occurs for molding processes.

A problem in calculating the cost is the fact that the tools have a limited lifetime and that the 
lifetime in some cases depend on the type of material. This can be handled by the proposed method since material cost is treated as a function of for example production volume. The resulting cost curve will then 'jump' each time the production volume reaches a multipla of the tool life as shown in figure 9.

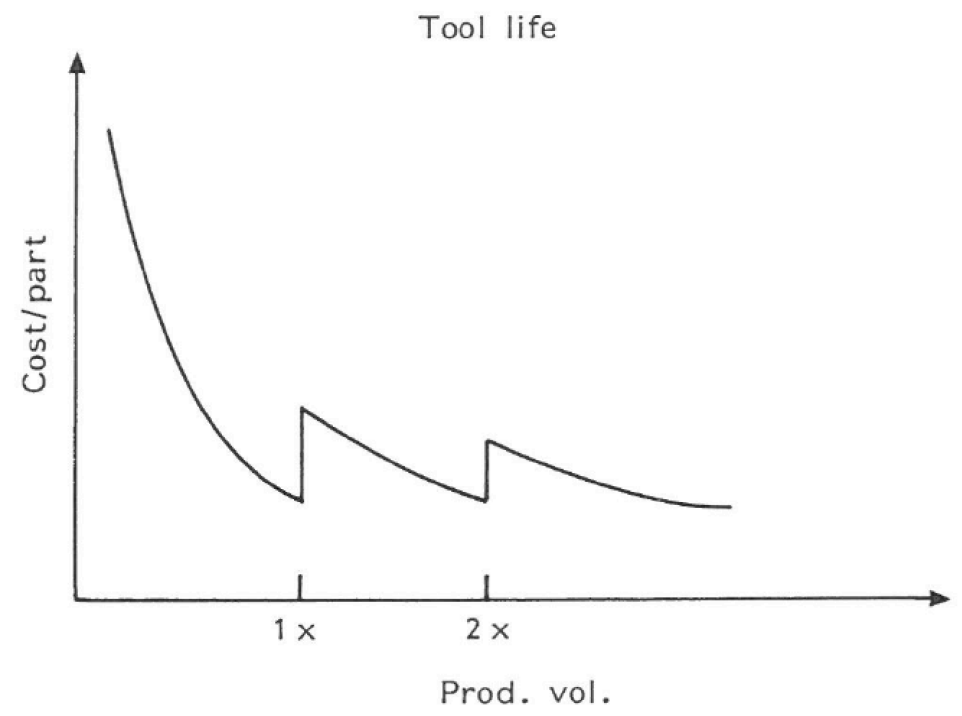

Figure 8 Cost curve which takes tool life into account.

\section{CONCLUSION}

Different costing methods are being applied to different design stages. For the conceptual design stage, functional costing and quick costing techniques are used for selecting among alternative concepts, to make quotations and to detect cost reduction areas. In the embodiment and detailed design phases cost estimation is used for selecting among alternative production methods and to support cost optimization. Several costing methods for evaluation of production methods are reported in the literature, but most of them are targeted towards part optimization. Because of the detailed information about production method which is required in these methods they are not suited for early selection of production methods. Only two methods for this purpose were found and another four methods could be used at the same design level but they had only cost information about a single production method. Based on previous industrial studies and on the literature review requirements to costing methods for selection of production methods have been set up. A concept for this purpose is suggested. It is capable of handling sequences of production methods, different materials, and both single parts and products. It allows tool lifetime and maintenance to be included in the cost.

\section{Acknowledgment}

This work is partly sponsored by the Danish Technical Research Council under the program for Integrated Production Systems (IPS).

\section{References:}

1. Ehrlenspiel, K. and Hillebrand, A Konstruieren und Kalkulieren am Bildschirm, VDIBerichte Nr. 610.2, Düsseldorf, 1986.

2. Esawi, A and Ashby, M F. Cost estimation techniques for the early stages of design, Internal report from Cambridge University Engineering Department, 1993

3. Pahl, G. and Beitz, W. Engineering Design, Springer Verlag, 1984

4. Diels, H. Kostenwachstumsfunktionen - ein Hilfsmittel zur Kostenfrüerkennung im 
Konstruktionsprocess, ICED'85, Hamburg august 1985, p.437-449.

5. Bush, S A and Sheldon, D F. Whose cost is it anyway?, ICED'93, The Hague, p. 11301135.

6. Sheldon, D F; Perks, R; Jackson, M; Miles, B L and Holland, J. Designing for whole life costs at the concept stage, Journal of Engineering Design, Vol. 1. No. 2, 1990, p.131-145.

7. VDI 2235, Wirtschaftliche Entscheidungen beim konstruieren, Methoden und Hilfen, oct. 1987.

8. Ehrlenspiel, K. Kostengünstig Konstruiren, Springer Verlag, 1985

9. Creese, R.C., Adithan M., Pabla B.S., Estimating and costing for the metal manufacturing Industries, Marcel Dekker, Inc. 1992.

10. Ferreirinha, P. Kalkulationssystem fuer neuentwicklungen mit anwndung von funktionskosten, ICED'83, København 1983, p.166-173.

11. French, M J. Function costing: A potential aid to designers, Journal of Engineering Design, Vol.1. no.1. 1990, p. 47-53.

12. Li, M; Stokes, C A; French, M J and Widden; M B. Function-costing: Recent developments, ICED'93, The Hague, August 1993, p.1123-1129.

13. Bradford, D T and Culley S J. A strategy for costing at the concept stage of design, ICED'89, 1989, p.425-434.

14. Jakobsen, K. The interrelation between product shape, material and production method, ICED'89, Harroegate, august 1989, pp. 775-784.

15. Haudrum, J. and Alting, L. Structured Methods for Process Selection in the Stage of Design, Proceedings of ICCIḾM3, september 1993, Singapore, pp. 143-154.

16. Haudrum, J. How to incorporate Production Method Information into the Embodiment Design, 4. Symposium Fertigungsgerichtes Konstruieren, 14./15. October 1993, Egloffstein, Germany.

17. Boothroyd, G. Estimate costs at an early stage. American Machinist, august 1988, pp. 54-57.

18. Boothroyd, G and Reynolds, C. Approximate Cost Estimates for Typical Turned Parts. Journal of Manufacturing Systems vol. 8/No. 3, University of Rhode Island, Kingston, pp. 185-193.

19. Boothroyd, $\mathrm{G}$ and Radovanovic, P. Estimating the Cost of Machined Components During the Conceptual design of a Product. Annals of the CIRP vol. 38/1/1989, pp. 157-160. 20. Dewhurst, P and Boothroyd, G. Early Cost Estimating in Product design. Journal of Manufacturing Systems vol. 7/No. 3, pp. 183-191.

21. Dewhurst, P and Blum, C. Supporting Analasys for the Economic Assessment of Diecasting in Product Design.Annals of the CIRP vol. 38/1/1989, pp. 161-164.

22. Boothroyd, $G$ and Dewhurst, P. Design for Manufacture and Assembly software packet. 23. Spur, G and Kreisfeld, P. Hilfsmittel zur Kostenprognose abgespanter Einzelteile. VDIBerichte Nr. 457, 1982, pp. 91-102.

24. Kreisfeld, P. Exakte Kostenprognose von Rotationsteilen durch Bildung von Kostenfamilien. Industrie, Nr. 18 v. 4. 3, 1986, pp. 45-46.

25. Gopalakrishnan, B and Pathak, M A. Machine Parameter Selection and Cost Estimation techniques: Applications in Concurrent Engineering. Manufacturing International, ASME, $\underline{1992}$, pp. 249-256.

26. Ott, H and Hubka, V Ueberschagige Herstellkostenberechnung für Maschinenteile in der Entwurfsphase, ICED 1983, Copenhagen, pp. 179-188.

27. Ehrlenspiel, K and Rutz, A. Drei Beispiele zur rechnerunterstützten Kostenberechnung in Konstruktion und Arbeitsvorbereitung. VDI-Berichte Nr. 492, 1983, pp. 89-104.

28. Poli, C; Escudero, J and Fernandez, R. How Part Design Affects Injectionmolding Tool Costs. Machine Design, november 1988, pp. 101-104.

29. Rosen, D W.; Dixon, J R.; Poli, C and Xin D. Features and Algorithms for Tooling Cost Evaluation in Injection Molding and Die Casting. Computers In Engineering, vol. 1, ASME, 
1992, pp. 45-52.

30. Poli, C; Kuo, S M and Graves, R J. Design for Injection Molding: a Group-technologybased Approach. Jounal of Engineering Design, vol. 3, No. 4, 1992, pp. 307-324.

31. Johansen, O. Omkostningskalkulation for sprøjtest øbte emner herunder beregning af cyklustid og valg af maskinstørrelse, Danmarks Tekniske Universitet 1994, Publ.nr. PT.94.01. 32. Han, Y C; Park, J C; Clark, J P and Field, F R. Spreadsheet Based Cost Estimation for the P/M Fabrication Process. Proceedings of the 1988 International Powder Metallurgy Conference, vol. 21, pp. 723-733.

33. Knight, W A. Design for Manufacture Analysis: Early Estimates of Tool Costs for Sintered Parts, Annals of the CIRP Vol. 40/1/1991, pp. 131-134.

34. Knight, W A and Poli, C A. Systematic Approach to Forging Design. Machine Design, january 1985, pp. 94-99.

35. Haan, T.J.A. Cost Estimating During the design process. Proceeding of ICED 1983, vol. 1, pp. 174-178.

36. Pacyna, H; Hillebrand, A and Rutz, A. Kostenfrüherkennung für Gussteile, VDIBerichte Nr. 457, 1982, pp. 103-114.

37. Ferreirinha, P. Herstellkostenberechnung von Machinteilen in der Entwurfsphase mit dem HKB Program. Proceeding of ICED 1985, pp. 461-467.

38. Ferreirinha, P. Rechnerunterstützte Vorkalkulation im Machinenbau für Konstrukteure und Arbeitsvorbereiter mit "HKB". Proceeding of ICED 1990, pp. 1346-1353.

39. Zenger, D C. A cost based approach to the selection of materials and processes in product design, ICED'93, Thague, August 17-19, 1993, pp. 1136-1143.

40. Allen, A J; Swift, K G and Hird, G A. Process Selection and Component Costing System in Support of Product Design, Autotech 91, NEC, Birmingham, UK.

41. Allen, A J; Bielby, M S and Swift, K G. Development Of a Product Manufacturing Analysis And Costing System, International Forum on Product Design for Manufacture \& Assembly, Newport Rhode Island, 14-15 may, 1990.

42. Allen, A J and Swift, K G. Manufacturing Process selection and costing, Proc. Instn. Mech. Engrs. Vol 204, 990, pp. 143-148.

43. Haudrum, J. Role-playing used for studying how process selection is caried out in product design, The seventh IPS research seminar, Fugls $\emptyset$, Oct. 1992, s.97-112.

44. Haudrum, J and Mortensen, N H. Ten Studies of how Process Selection is carried out in the Stage of Design - A Pilot Project (In Danish), report, Institute of Manufacturing Engineering, Tecnical University of Denmark, PI 93.07-A/AP 93.20, june 1993, $140 \mathrm{~s}$. 45. Lenau, T. Models of manufacturing processes for design information systems, Manufacturing Systems, Vol 21, no.2. 1992, pp. 129-135.

46. Lenau, T. and Kristensen L. MADED - an information system for manufacturing processes, ICED'93, Haag, Holland, august 1993, s. 1093-1096.

47. Lenau, T. and Kristensen, L. MADED - An information system for Manufacturing processes, The seventh IPS research seminar, Fugls $\emptyset$, Oct. 1992, s.67-84.

48. Jepsen, E L. Valg af industrielle fremstillingsmetoder, PhD.-thesis, AMT, Danmarks Tekniske Højskole, 1978.

49. Tvenge, K. Værktøjsprincipper - Pulverpresning, Danmarks Tekniske Højskole, AMT, 1981, AP.81.27 